\title{
Mechanisms of endothelium-dependent relaxation evoked by anandamide in isolated human pulmonary arteries
}

\author{
Marta Baranowska-Kuczko • Hanna Kozlowska • Mirosław Kozłowski • \\ Eberhard Schlicker • Monika Kloza • Arkadiusz Surażyński • Emilia Grzęda • \\ Barbara Malinowska
}

Received: 27 November 2013 / Accepted: 6 February 2014 / Published online: 28 February 2014

(C) The Author(s) 2014. This article is published with open access at Springerlink.com

\begin{abstract}
Endocannabinoids contract, relax or do not affect vessels with different calibre and tone in the pulmonary circulation in four species. The aim of the present study was to determine the mechanisms involved in the anandamideinduced relaxation of human pulmonary arteries (hPAs). Studies were performed in the isolated hPAs pre-constricted with the prostanoid TP receptor agonist, U-46619. To detect fatty acid amide hydrolase (FAAH) expression, Western blots were used. Anandamide concentration dependently relaxed the endothelium-intact hPAs pre-constricted with U-46619. The anandamide-induced relaxation was virtually abolished by removal of the endothelium and strongly attenuated by inhibitors of cyclooxygenases (indomethacin, COX-1/COX2 , and nimesulide, COX-2), nitric oxide synthase ( $N^{G}$-nitro-Larginine methyl ester) given separately or in combination, FAAH (URB597), and the prostanoid IP receptor antagonist,
\end{abstract}

M. Baranowska-Kuczko • H. Kozłowska • M. Kloza • E. Grzęda •

B. Malinowska

Department of Experimental Physiology and Pathophysiology,

Medical University of Białystok, Mickiewicz Str. 2A,

15-222 Białystok, Poland

M. Baranowska-Kuczko ( $\square)$

Department of Clinical Pharmacy, Medical University of Białystok, Mickiewicz Str. 2A, 15-222 Białystok, Poland

e-mail:mabar@umb.edu.pl

E. Schlicker

Department of Pharmacology and Toxicology, University of Bonn, Sigmund-Freud-Str. 25, 53127 Bonn, Germany

M. Kozłowski

Department of Thoracic Surgery, Medical University of Białystok, M.C. Skłodowska Str. 4A, 15-276 Białystok, Poland

A. Surażyński

Department of Medicinal Chemistry, Medical University of

Białystok, Mickiewicz Str. 2D, 15-222 Białystok, Poland
RO1138452. The anandamide-evoked relaxation in the endothelium-intact vessels was attenuated in $\mathrm{KCl}$ preconstricted preparations or by the inhibitor of largeconductance $\mathrm{Ca}^{2+}$-activated $\mathrm{K}^{+}$channels, iberiotoxin. In experiments performed in the presence of URB597 to exclude effects of anandamide metabolites, the antagonist of the endothelial cannabinoid receptor, O-1918, diminished the anandamide-evoked relaxation whereas the antagonists of cannabinoid $\mathrm{CB}_{1}, \mathrm{CB}_{2}$ and vanilloid TRPV1 receptors, AM251, SR144528 and capsazepine, respectively, had no effect. Western blot studies revealed the occurrence of FAAH protein in the hPAs. The present study shows that anandamide breakdown products, cyclooxygenase pathways, nitric oxide, potassium channels and the O-1918-sensitive cannabinoid receptor play a role in the anandamide-induced relaxation of the hPAs with intact endothelium.

Keywords Human pulmonary artery $\cdot$ Anandamide $\cdot$ Nitric oxide $\cdot$ Prostacyclin $\cdot$ Potassium channels $\cdot$ O-1918-sensitive cannabinoid receptor

\section{Introduction}

Pulmonary arterial hypertension (PAH) is a progressive, potentially lethal disease. Patients with PAH have increased levels of potent vasoconstrictors and decreased levels of the endothelial vasodilator nitric oxide (NO) and prostacyclin $\left(\mathrm{PGI}_{2}\right)$, leading to enhanced vasoconstriction, thrombosis, and pulmonary vascular remodelling (Frumkin 2012). Available therapies for PAH target the imbalance of vasoconstricting and vasodilating mediators leading to vasorelaxation in pulmonary vasculature (Frumkin 2012; Waxman and Zamanian 2013; Benyahia et al. 2013). However, to date, PAH is incurable with the currently approved medications, and there is an urgent need for alternative treatment strategies. 
Hornig (2007) has suggested that endocannabinoids may represent a future option in the PAH therapy.

The two best known endocannabinoids, anandamide $(N-$ arachidonoylethanolamine $)$ and 2 arachidonoylglycerol (2-AG), influence the diameter of systemic blood vessels by various mechanisms (Montecucco and Di Marzo 2012), and their possible role has also been studied in the pulmonary vasculature. Endogenous anandamide was detected in the lung of the rabbit (Wahn et al. 2005), the mouse (Wenzel et al. 2013) and the rat (Calignano et al. 2000), and endogenous 2-AG was found in the rabbit lung (Wahn et al. 2005). Moreover, fatty acid amide hydrolase (FAAH), the enzyme responsible for anandamide degradation, was detected in rabbit and murine lungs (Wahn et al. 2005; Wenzel et al. 2013) and in human pulmonary artery smooth muscle cells (Meng et al. 2008; Wenzel et al. 2013). However, only few functional studies concerning direct actions of endocannabinoids on the pulmonary vasculature have been published in the latter four mammalian species in vivo or in vitro.

In the isolated, ventilated, and buffer-perfused lung of the rabbit, both anandamide and 2-AG increased the pulmonary arterial pressure whereas $R$-methanandamide (a metabolically stable analogue of anandamide) and noladin ether, a third endocannabinoid (which is also metabolically stable), failed to do so (Wahn et al. 2005). These data are similar, although not identical, to those obtained in the isolated perfused lung system of mice where anandamide but not 2-AG or $R$ methanandamide increased the pulmonary arterial tone (Wenzel et al. 2013). The explanation for the vasopressor effect of anandamide is that this endocannabinoid is degraded by FAAH into arachidonic acid products which in turn are converted to vasoactive agents by cyclooxygenase-2 (COX-2) (Wahn et al. 2005) and COX and/or lipooxygenase (Wenzel et al. 2013). The involvement of cannabinoid $\mathrm{CB}_{1}$ receptors could be discarded in the rabbit and mouse lungs (Wahn et al. 2005; Wenzel et al. 2013). With respect to the rabbit lung, the vanilloid transient receptor potential cation channel of V1 type (TRPV1) receptor could also be excluded (Wahn et al. 2005), which, like $\mathrm{CB}_{1}$ or $\mathrm{CB}_{2}$ receptors, is a typical target of anandamide and is known to elicit dilatation in some vascular beds of the systemic circulation (for review, see Montecucco and Di Marzo 2012). On the other hand, in another preparation of rabbits, i.e. pre-constricted, isolated pulmonary arteries, noladin ether relaxed the rabbit pulmonary artery smooth muscle (Su and Vo 2007). Two mechanisms are involved in the latter effect, namely, the activation of cannabinoid $\mathrm{CB}_{1}$ receptors and, in addition, the activation of O-1918sensitive receptors. The molecular and biological properties of the latter receptors that have been identified in a series of vascular beds of the systemic circulation
(Montecucco and Di Marzo 2012) are so far poorly understood.

The effect of endocannabinoids has also been studied in isolated pulmonary arteries of mice, rats and humans. In nonpre-constricted preparations of rats and mice, anandamide was devoid of an effect (Baranowska-Kuczko et al. 2012; Wenzel et al. 2013). On the other hand, anandamide induced a vasorelaxant effect in pre-constricted pulmonary arteries from rats (Baranowska-Kuczko et al. 2012) and humans (Kozłowska et al. 2007). In rat pulmonary arteries, this effect involves O-1918-sensitive but not $\mathrm{CB}_{1}$ and TRPV1 receptors; in addition, COX products play an important role (Baranowska-Kuczko et al. 2012). With respect to human pulmonary arteries (hPAs), virodhamine (a fourth endocannabinoid) shows a vasorelaxant effect again related to the activation of O-1918-sensitive receptors and the formation of COX products (Kozłowska et al. 2008). Our previous data (Kozłowska et al. 2008) do not allow to conclude whether $\mathrm{CB}_{1}$ and TRPV1 receptors play a role as well since virodhamine has a low or missing intrinsic activity at $\mathrm{CB}_{1}$ receptors and does not bind to TRPV1 receptors (for review, see Pertwee et al. 2010). Moreover, anandamide, which showed a vasodilatory effect as well, has been studied in the presence of a $\mathrm{CB}_{1}$ receptor antagonist only, and the mechanisms of its vascular effect have not been examined (Kozłowska et al. 2007). So, the aim of the present study was to examine the receptors and mechanisms involved in the effect of anandamide in hPAs. We found that the anandamide-induced vasorelaxation is strongly endothelium dependent and involves arachidonic acid degradation products, $\mathrm{NO}$ and big-conductance $\mathrm{Ca}^{2+}$-activated $\mathrm{K}^{+}$channels $\left(\mathrm{BK}_{\mathrm{Ca}}\right)$ and, in addition, is related to the activation of O-1918-sensitive receptors but not cannabinoid $\mathrm{CB}_{1}, \mathrm{CB}_{2}$ or vanilloid TRPV1 receptors.

\section{Materials and methods}

All protocols were approved by the Human Ethical Committee of the Medical University of Białystok (no. R-I002/309/2008). Tissue donors had provided informed consent for the use of their vessels.

\section{Pulmonary artery preparation}

Human lung tissue was obtained from 41 patients ( 35 men and 6 women, mean age of $66.4 \pm 0.7$ years including $88 \%$ smokers) undergoing lobectomy or pneumonectomy during resection of lung carcinoma. Pre-operative echocardiography revealed normal left and right ventricular function in each case. Patients did not have any clinical evidence of pulmonary hypertension. Before the operation, all patients received cephalosporins and low-molecular-weight heparin as infection and 
thrombosis prophylaxis, respectively. The tissue was transported to the laboratory within half an hour in a cold $\left(4{ }^{\circ} \mathrm{C}\right)$, pre-gassed Tyrode's bicarbonate solution (for composition, see below at section "Organ bath technique"). Lobar and segmental hPA branches were cleaned from the lung parenchyma and cut into rings (from the middle portion of each artery, 3- to 5-mm length and 2- to 4-mm outer diameter).

Organ bath technique

The arterial rings were suspended on stainless steel wires in 10-ml organ baths containing Tyrode's solution (concentration in millimolar: $\mathrm{NaCl}, 139.2 ; \mathrm{KCl}, 2.7 ; \mathrm{CaCl}_{2}, 1.8 ; \mathrm{MgCl}_{2}, 0.49$; $\mathrm{NaHCO}_{3}, 11.9 ; \mathrm{NaH}_{2} \mathrm{PO}_{4}, 0.4$; glucose, 5.5) and were gassed continuously with $95 \% \mathrm{O}_{2}$ and $5 \% \mathrm{CO}_{2}$, at $37{ }^{\circ} \mathrm{C}$ and $\mathrm{pH} 7.4$. Pulmonary artery rings were allowed to equilibrate for $90 \mathrm{~min}$; during this time period, the bath fluid was exchanged every 10 min with fresh Tyrode's solution. The optimal resting tension was about $20-25 \mathrm{mN}$ (depending on the rings' internal diameter), which ensured that responses to agonists were maximal. Muscle tension was recorded by a force displacement transducer (PIM 100RE, BIO-SYS-TECH, Białystok, Poland) and displayed on a computer.

After the equilibration period, all rings were pre-constricted sub-maximally with $(-)$ phenylephrine $(1 \mu \mathrm{M})$ to prime the tissues and to assess the integrity of the endothelium (at least $80 \%$ relaxation in response to acetylcholine $1 \mu \mathrm{M}$ was designated as endothelium-intact). When necessary, the endothelium was removed by gentle rubbing of the intima. The absence of acetylcholine-induced vasorelaxation was verified as successful endothelial denudation.

Viable vessels were constricted sub-maximally with U-46619 (0.01-0.03 $\mu \mathrm{M}$; a prostanoid TP receptor agonist). In some experiments, serotonin $(5-\mathrm{HT}, 1 \mu \mathrm{M})$ or high-KCl $(60 \mathrm{mM})$ Tyrode's solution prepared by equimolar substitution of $\mathrm{NaCl}$ by $\mathrm{KCl}$ was used to pre-constrict the rings. When a stable level of tone was maintained (after about $45 \mathrm{~min}$ of exposure time), concentration-response curves (CRCs) were generated by cumulative application of anandamide. The agonist was added in steps of $0.5 \log$ units with about $8-10 \mathrm{~min}$ between each application. Controls were obtained by the addition of Tocrisolve. All experiments were performed in paired vessels; control and anandamide-treated responses were studied on vessels from the same patient. Only one curve was determined in each individual preparation. In an additional series of experiments, complete CRCs of U-46619 were recorded $30 \mathrm{~min}$ after administration of anandamide $10 \mu \mathrm{M}$ or Tocrisolve.

To determine the mechanisms of the vasorelaxant effects of anandamide, some tissues were pre-treated for $30 \mathrm{~min}$ (if not stated otherwise) with the following antagonists/inhibitors alone or in combination (details are provided in brackets): 30-min treatment with AM251 $1 \mu \mathrm{M}$ (cannabinoid $\mathrm{CB}_{1}$ receptor), SR144528 $1 \mu \mathrm{M}$ ( $\mathrm{CB}_{2}$ receptor), O-1918 $10 \mu \mathrm{M}$ (endothelial cannabinoid receptor), RO1138452 $1 \mu \mathrm{M}$ (prostanoid IP receptor), URB597 $1 \mu \mathrm{M}$ (FAAH), 45-min incubation with capsazepine $1 \mu \mathrm{M}$ (vanilloid TRPV1 receptor), indomethacin $10 \mu \mathrm{M}(\mathrm{COX}-1 / \mathrm{COX}-2)$, nimesulide $10 \mu \mathrm{M}$ (COX-2), $N^{G}$-nitro-L-arginine methyl ester (L-NAME) $300 \mu \mathrm{M}$ (NO synthase), and iberiotoxin $0.1 \mu \mathrm{M}$ (large-conductance $\mathrm{Ca}^{2+}$-activated $\mathrm{K}^{+}$channels). Antagonists/inhibitors were also present during the construction of the CRCs.

The resting tension was not affected by most of the drugs but slightly decreased by nimesulide and ethanol. Therefore, slightly different U-46619 concentrations $(0.01-0.03 \mu \mathrm{M})$ were used in experiments with the latter agents to achieve comparable contraction levels (see Table 1 for details). URB597, RO1138452, capsazepine, nimesulide and O-1918 were dissolved in ethanol, and the effects of the appropriate vehicle on the relaxation to anandamide were also tested when the final bath concentration exceeded $0.1 \%(v / v)$. No significant effects of vehicle on the CRCs were observed (see Table 1 for details).

\section{Preparation of tissue extracts}

The hPAs and lungs were homogenized $(20 \% w / v)$ in $0.05 \mathrm{~mol} / \mathrm{l}$ Tris-HCl, $\mathrm{pH} 7.6$, with the use of a knife homogenizer (Polytron) and were subsequently sonicated at $0{ }^{\circ} \mathrm{C}$. Homogenates were centrifuged at $16,000 \times \mathrm{g}$ for $30 \mathrm{~min}$ at $4{ }^{\circ} \mathrm{C}$. The supernatant was used for protein determination (Bradford method) and Western blot analysis.

\section{Western blot analysis}

Slab sodium dodecyl sulphate polyacrylamide gel electrophoresis (SDS/PAGE) was used, according to the method by Laemmli (1970). Equal amounts (about $100 \mu \mathrm{g}$ ) of protein were electrophoresed. After SDS/PAGE, the gels were allowed to equilibrate for $5 \mathrm{~min}$ in $25 \mathrm{mM}$ Tris plus $0.2 \mathrm{M}$ glycine in $20 \%(\mathrm{v} / \mathrm{v})$ methanol. The proteins were transferred to $0.2 \mu \mathrm{m}$ pore-sized nitrocellulose at $25 \mathrm{~mA}$ for $1 \mathrm{~h}$ by using a LKB 2117 Multiphor II electrophoresis unit. The nitrocellulose was incubated with rabbit polyclonal anti-FAAH antibody at a concentration of 1:500 and rabbit polyclonal anti- $\beta$ actin antibody at a concentration of 1:500 in $5 \%$ dried milk in Tris-buffered saline with Tween 20 (TBS-T) $(20 \mathrm{mM}$ Tris- $\mathrm{HCl}$ buffer, pH 7.4, containing $150 \mathrm{mM} \mathrm{NaCl}$ and $0.05 \%$ Tween $20)$ overnight. In order to analyze FAAH and $\beta$-actin, a second antibody, i.e. anti-rabbit IgG (whole molecule) conjugated with alkaline phosphatase, was added at a concentration of 1:5000 in TBS-T and incubated for $1 \mathrm{~h}$ under continuous shaking. Then nitrocellulose was washed with TBS-T $(5 \times$ $10 \mathrm{~min}$ ) and submitted to 5-bromo-4-chloro-3-indolyl phosphate/nitro blue tetrazolium (BCIP/NBT) liquid substrate reagent. 
Table 1 Influence of various treatments on the relaxant effect to anandamide in endothelium-intact human pulmonary arteries pre-constricted with $\mathrm{U}-46619$, serotonin or $\mathrm{KCl}$

\begin{tabular}{|c|c|c|c|c|c|}
\hline Group & $n$ & Tension $(\mathrm{mN})$ & $\mathrm{pEC}_{25}$ & $\mathrm{pEC}_{50}$ & $R_{\max }(\%)^{\mathrm{a}}$ \\
\hline Control (0.01-0.03 $\mu \mathrm{M}$ U-46619 pre-constricted) & 21 & $10.0 \pm 0.4$ & $5.7 \pm 0.1$ & $5.0 \pm 0.1$ & $90 \pm 7$ \\
\hline -Endothelium & 7 & $13.7 \pm 2.8$ & - & - & $23 \pm 11 * * *$ \\
\hline L-NAME (300) & 4 & $10.0 \pm 1.1$ & $4.2 \pm 0.1 * * *$ & - & $36 \pm 10 * * *$ \\
\hline Indomethacin (10) & 7 & $10.7 \pm 1.8$ & - & - & $28 \pm 10 * * *$ \\
\hline L-NAME (300)+indomethacin (10) & 3 & $8.4 \pm 0.8$ & - & - & $11 \pm 9 * * *$ \\
\hline RO1138452 (1) & 5 & $10.0 \pm 2.0$ & $4.5 \pm 0.3 * *$ & - & $30 \pm 5 * * *$ \\
\hline Iberiotoxin $(0.1)$ & 5 & $8.7 \pm 1.0$ & $4.5 \pm 0.1 * * *$ & - & $39 \pm 8$ \\
\hline URB597 (1) & 12 & $12.9 \pm 1.5$ & $5.1 \pm 0.2 *$ & $4.3 \pm 0.1 * *$ & $65 \pm 3 * *$ \\
\hline URB597 (1) + AM251 (1) & 7 & $10.0 \pm 1.8$ & $5.2 \pm 0.2$ & $4.4 \pm 0.1$ & $63 \pm 9$ \\
\hline URB597 (1) + SR144528 (1) & 6 & $10.9 \pm 2.2$ & $4.8 \pm 0.2$ & $4.7 \pm 0.1$ & $76 \pm 10$ \\
\hline URB597 (1) + capsazepine (1) & 7 & $10.5 \pm 1.2$ & $4.8 \pm 0.1$ & $4.5 \pm 0.2$ & $72 \pm 14$ \\
\hline URB597 (1) + O-1918 (10) & 7 & $10.3 \pm 1.5$ & $4.4 \pm 0.1^{\dagger}$ & - & $38 \pm 3^{\dagger}$ \\
\hline Control (ethanol $0.1 \% v / v$ ) & 5 & $7.9 \pm 2.0$ & $6.0 \pm 0.1$ & $5.1 \pm 0.2$ & $97 \pm 9$ \\
\hline Nimesulide (10) & 5 & $7.1 \pm 1.0$ & $5.2 \pm 0.4^{*}$ & $4.5 \pm 0.1^{*}$ & $75 \pm 15$ \\
\hline Control $(1 \mu \mathrm{M}$ serotonin pre-constricted $)$ & 5 & $8.8 \pm 0.5$ & $5.3 \pm 0.2$ & $4.8 \pm 0.1$ & $85 \pm 8$ \\
\hline Control (60 mM KCl pre-constricted) & 5 & $11.4 \pm 2.5$ & - & - & $25 \pm 12^{\circ 00}$ \\
\hline
\end{tabular}

Data are expressed as the mean \pm SEM of $n$ independent experiments

Some experiments were performed in endothelium-denuded rings (-endothelium). If not stated otherwise, micromolar concentrations of chemicals are provided in brackets

$L-N A M E N^{G}$-nitro-L-arginine methyl ester

${ }^{*} P<0.05 ; * * P<0.01 ; * * * P<0.001$, compared with the respective control group; ${ }^{\dagger} P<0.05$, compared with URB597 alone; ${ }^{\circ 00} P<0.001$, compared with the control obtained in the presence of U-46619

${ }^{a}$ Relaxant effect at the highest anandamide concentration $(100 \mu \mathrm{M})$

\section{Drugs used}

Acetylcholine chloride, (-) phenylephrine hydrochloride, serotonin (creatinine sulphate complex) and L-NAME (Sigma, Munich, Germany) were dissolved in deionized water. Indomethacin (Sigma) was dissolved in $0.5 \mathrm{M} \mathrm{NaHCO}_{3}$. Anandamide was purchased from Tocris (Bristol, UK) as a $10-\mathrm{mg} / \mathrm{ml}$ emulsion in soya water (1:4) and was further diluted with deionized water. Stock solutions $(10 \mathrm{mM})$ of capsazepine, AM251 ( $N$-(piperidin-1-yl)-5-(4-iodophenyl)1-(2,4-dichlorophenyl)-4-methyl-1H-pyrazole-3carboxamide), nimesulide (Tocris), URB597 ( $3^{\prime}$ - ( a minocarbony 1$)\left[1,1^{\prime}\right.$ - bi i henyl]-3-yl)cyclohexylcarbamate), RO1138452 (4,5-dihydro- $N$-[4-[[4-(1methylethoxy)phenyl]methyl]phenyl]-1 $H$-imidazol-2-amine) (Cayman Chemicals, Ann Arbor, MI, USA) and SR 144528 ( $N$-[(1S)-endo-1,3,3-trimethyl bicyclo[2.2.1]heptan-2-yl]5-(4-chloro-3-methylphenyl)-1-(4-methylbenzyl)-pyrazole-3carboxamide) (Sanofi-Aventis, Montpellier, France) were prepared in ethanol and further diluted in distilled water. U-46619 ((5Z)-7-[(1R,4S,5S,6R)-6-[(1E,3S)-3-hydroxy-1-octenyl]-2oxabicyclo[2.2.1]hept-5-yl]-5-heptenoic acid) and O-1918 (1,3-dimethoxy-5-methyl-2-[(1R,6R)-3-methyl-6-(1methylethenyl)-2-cyclohexen-1-yl]-benzene) (Cayman) were supplied in methyl acetate, which was evaporated under a stream of nitrogen, and ethanol was added as a solvent. These agents were diluted to their final concentrations with deionized water. Anti-FAAH antibodies were purchased from Cayman (cat. no. 101600) and anti- $\beta$-actin and anti-rabbit IgG alkaline phosphatase antibodies from Sigma-Aldrich (St. Louis, MO, USA).

Calculations and statistical analysis

Contractile responses to U-46619 are shown as a percentage of the contraction induced by $60 \mathrm{mM} \mathrm{KCl}$ (Kozłowska et al. 2007, 2008). Vasodilatory effects of anandamide or its solvent are expressed as the percentage relaxation of the isometric contraction induced by U-46619, 5-HT or KCl. In analogy to our previous study (Baranowska-Kuczko et al. 2012), the extent of relaxation at $100 \mu \mathrm{M}$ anandamide was quantified as a rough measure of the maximum extent of relaxation obtainable $\left(R_{\max }\right)$. Since some experimental procedures attenuated the $R_{\max }$ of anandamide by more than $50 \%$, the concentrations causing a relaxation of $25 \%$ of the pre-contracted vessel were given (effective concentration for $25 \%\left(\mathrm{EC}_{25}\right)$ values). The half maximal effective concentration $\left(\mathrm{EC}_{50}\right)$ values (i.e. the concentrations causing a relaxation of $50 \%$ 
of the pre-contracted vessel) were used when $R_{\max }$ was at least $60 \%$. These values were calculated from the individual CRCs and are usually expressed as their negative decadic logarithms $\left(\mathrm{pEC}_{25}\right.$ and $\mathrm{pEC}_{50}$ ).

The rightward shift of the $\mathrm{CRC}$ of anandamide by the different experimental procedures (endothelium removal, enzyme blockers and receptor antagonists) was determined on the basis of the $\mathrm{EC}_{25}$ values. The results are expressed as the mean \pm SEM of $n$ experiments; $n$ always refers to the number of patients. For statistical analysis, Student's $t$ test for unpaired data was used. For comparisons of the CRCs of two or more treatment groups to the same control, analysis of variance (ANOVA) followed by Dunnett's test was performed (Prism 5, GraphPad Software, Inc., La Jolla, CA, USA). Differences were considered significant when $P<0.05$.

\section{Results}

Influence of anandamide on the hPAs pre-constricted with U-46619 or serotonin

The prostanoid TP receptor agonist U-46619 $(0.001-0.3 \mu \mathrm{M})$ induced a concentration-dependent contraction of hPA rings $\left(\mathrm{pEC}_{50}=7.7 \pm 0.1, n=3\right.$; Fig. 1). Anandamide $10 \mu \mathrm{M}$ and its vehicle Tocrisolve $(1 \mu \mathrm{l} / \mathrm{ml})$ did not modify the CRC of U-46619 $\left(\mathrm{pEC}_{50}=7.5 \pm 0.1, n=3 ; 7.5 \pm 0.1, n=4\right.$; Fig. 1 ) nor did they affect the basal tone of hPA rings. In most experiments, U-46619 was used to pre-contract the hPAs. The tension generated by U-46619 at $0.01-0.03 \mu \mathrm{M}$ (concentrations approximately equivalent to its $\mathrm{EC}_{60}$ ) did not differ



Fig. 1 Influence of anandamide and its solvent Tocrisolve on the concentration-dependent vasoconstriction induced by U-46619 in the endothelium-intact human pulmonary artery. The results are expressed as percentage of the isometric contraction induced by $\mathrm{KCl} 60 \mathrm{mM}$. Note that anandamide (although relaxing pre-constricted vessels) did not affect the basal tone. The mean \pm SEM of three to four tissues for each curve is presented. The SEM is smaller than or equal to the size of symbols in few cases significantly from that induced by 5-HT $1 \mu \mathrm{M}$ (approximately equivalent to its $\mathrm{EC}_{60}$; Kozłowska et al. 2007, 2008) or $\mathrm{KCl}$ $60 \mathrm{mM}$ (Table 1).

Anandamide caused almost full relaxation of the hPAs preconstricted with U-46619 (Fig. 2); the $\mathrm{pEC}_{25}$ and $\mathrm{pEC}_{50}$ values were 5.7 and 5.0, respectively (Table 1 ). The vasodilatation induced by anandamide was gradual in onset. Thus, it took $80 \mathrm{~min}$ to construct the whole CRCs. A typical trace of anandamide-induced relaxations in U-46619-pre-constricted arteries is shown in Fig. 2a. The following parameters had virtually no influence on the anandamide-evoked relaxation: use of 5-HT instead of U-46619 as pre-contracting agent (Fig. 3a), smoking habits (Fig. 3b), sex (Fig. 3c) and age (Fig. 3d).

Effects of endothelium removal and URB597 on the relaxation to anandamide

Removal of the endothelium very strongly reduced the vasodilator effect of anandamide (Fig. 2b, Table 1). Pre-treatment


Fig. 2 Representative original traces of the effects of anandamide and its vehicle (Tocrisolve) (a) and influence of endothelium removal and URB597 on the relaxant effect of anandamide in the human pulmonary artery (b). a The experiments were performed in separate vessels obtained from the same patient. The arrows indicate the application of the particular concentrations of anandamide or of its vehicle. $\mathbf{b}$ The results are expressed as the percentage relaxation of the isometric contraction induced by U-46619. The effects of Tocrisolve $(0.001-1.0 \% \mathrm{v} / \mathrm{v}$; vehicle of anandamide) are shown as well. The mean \pm SEM of 3-21 tissues for each curve is presented. The SEM is smaller than or equal to the size of the symbols in few cases 
Fig. 3 Influence of the preconstricting agent (a), smoking habits (b), sex (c) and age (d) of the patients on the relaxant effect of anandamide in the endothelium-intact human pulmonary artery. The results are expressed as the percentage relaxation of the isometric contraction induced by serotonin (5-HT) (a) or U-46619 (a-d). Results are given as the mean \pm SEM of the number of tissues (patients), namely a $n=5$ 5-HTpre-constricted and $n=21 \mathrm{U}$ 46619-pre-constricted, b 17 smokers and 4 non-smokers, c 6 women and 15 men and $\mathbf{d} 6$ patients $<60$ years $(54.4 \pm 1.2)$ and 15 patients $>60$ years $(67.1 \pm 0.7$; $P<0.001)$. Curves did not differ with respect to the $R_{\max }$ (vasorelaxant effect of anandamide $100 \mu \mathrm{M})$ and the $\mathrm{pEC}_{50}$ (range of 4.8-5.1). The SEM is smaller than or equal to the size of symbols in few cases
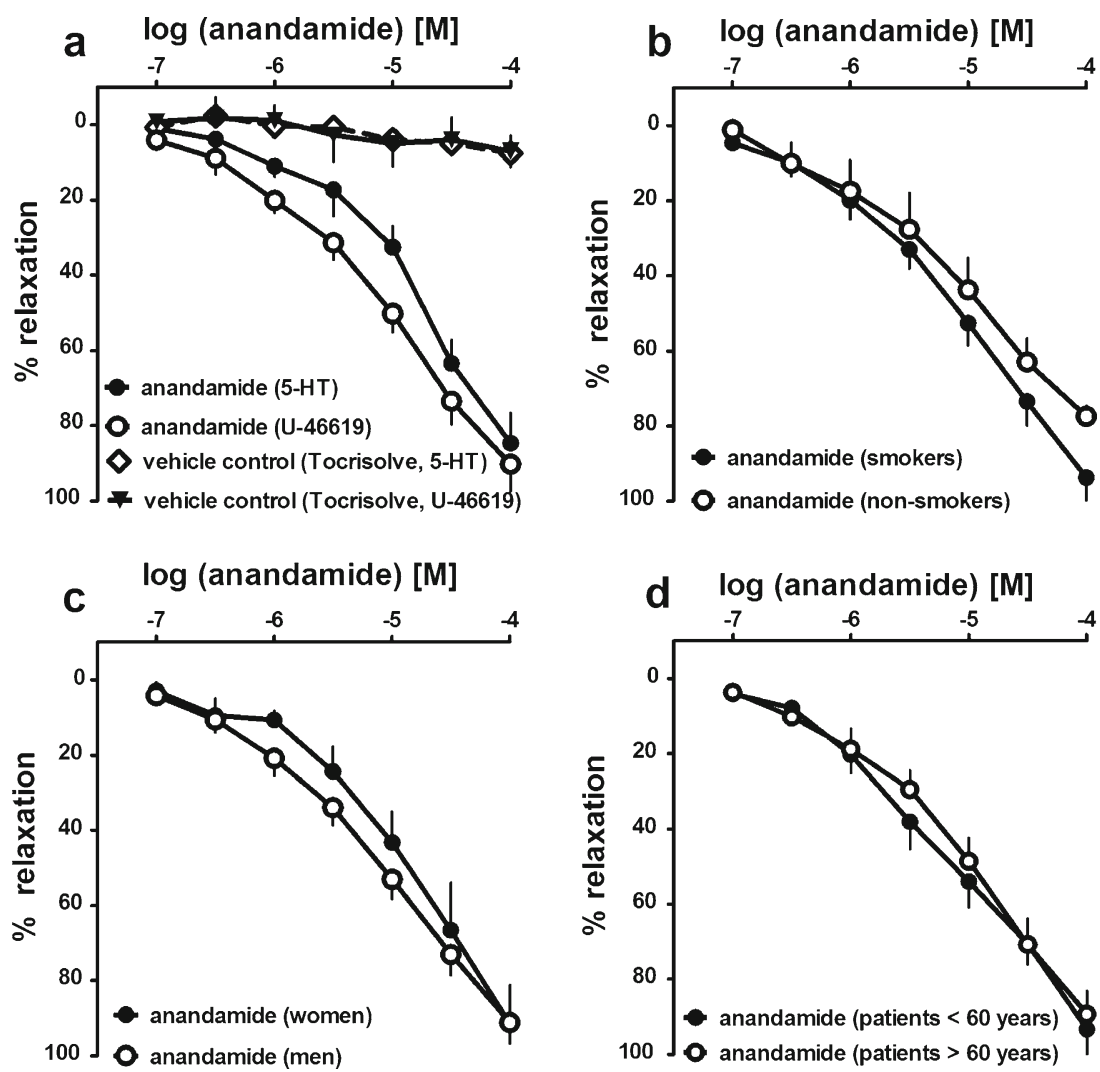

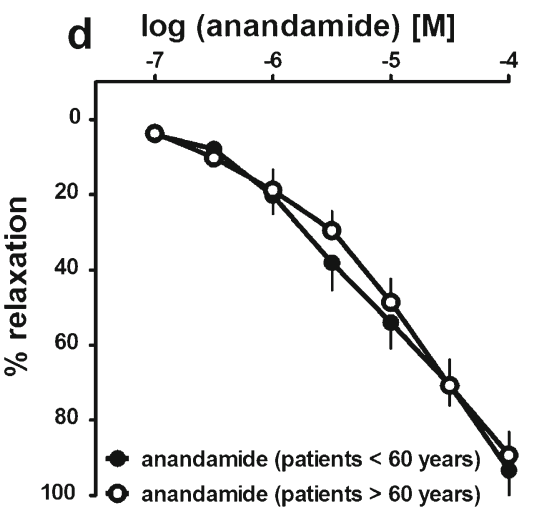

with the FAAH inhibitor URB597 $(1 \mu \mathrm{M})$ attenuated the anandamide-induced vasorelaxation in endothelium-intact hPAs (Fig. 2b), yielding a rightward shift by a factor of 4 . Moreover, the effect elicited by the highest concentration of the agonist was reduced by about $25 \%$ (for $\mathrm{pEC}_{25}$ and $R_{\max }$ values, see Table 1).

Effects of L-NAME, COX inhibitors and RO1138452 on the relaxation to anandamide

As shown in Fig. 4a, the NO synthase inhibitor L-NAME $(300 \mu \mathrm{M})$ and the COX-1/COX-2 inhibitor indomethacin $(10 \mu \mathrm{M})$ given separately or in combination reduced by about 55,60 or $80 \%$, respectively, the relaxant effect elicited by the highest concentration of anandamide $(100 \mu \mathrm{M})$ (for $R_{\max }$ value, see Table 1). Moreover, LNAME shifted to the right of the CRC for anandamide by a factor of 34 (for $\mathrm{pEC}_{25}$ value, see Table 1). The selective COX-2 inhibitor nimesulide $(10 \mu \mathrm{M})$ shifted to the right of the CRC for anandamide by a factor of 6 ; the effect elicited by the highest anandamide concentration was reduced by about $20 \%$ (Fig. $4 \mathrm{~b}$; for $\mathrm{pEC}_{25}, \mathrm{pEC}_{50}$ and $R_{\max }$ values, see Table 1). The prostanoid IP receptor antagonist RO1138452 $(1 \mu \mathrm{M})$ shifted the CRC for anandamide to the right by a factor of 16 and reduced the maximal effect of anandamide at $100 \mu \mathrm{M}$ by about $60 \%$ (Fig. $4 \mathrm{~b}$; for $\mathrm{pEC}_{25}$ and $R_{\max }$ values, see Table 1).

Effects of $\mathrm{KCl}$ and the $\mathrm{K}^{+}$channel blocker iberiotoxin on the relaxation to anandamide

In order to determine if potassium channels contribute to the vasodilator effects of anandamide, some experiments were carried out in $\mathrm{KCl}$ pre-constricted arteries and compared with U-46619-pre-constricted vessels. The vasorelaxation to anandamide at $100 \mu \mathrm{M}$ was reduced by about $65 \%$ in $\mathrm{KCl}$ pre-constricted arteries compared with arteries pre-constricted with U-46619 (Fig. 5; for $R_{\max }$ value, see Table 1). Pre-treatment with the selective blocker of big-conductance $\mathrm{Ca}^{2+}$-activated potassium channels, iberiotoxin $(0.1 \mu \mathrm{M})$, produced a 16 -fold rightward shift of the CRC for anandamide in U-46619-preconstricted arteries; the effect of anandamide $100 \mu \mathrm{M}$ was reduced by $50 \%$ (Fig. $5 ; \mathrm{pEC}_{25}$ and $R_{\max }$ values in Table 1).

Effects of cannabinoid and TRPV1 receptor antagonists on the relaxation to anandamide

As described above, the FAAH inhibitor URB597 $(1 \mu \mathrm{M})$ attenuated the anandamide-induced relaxation in hPAs 
a

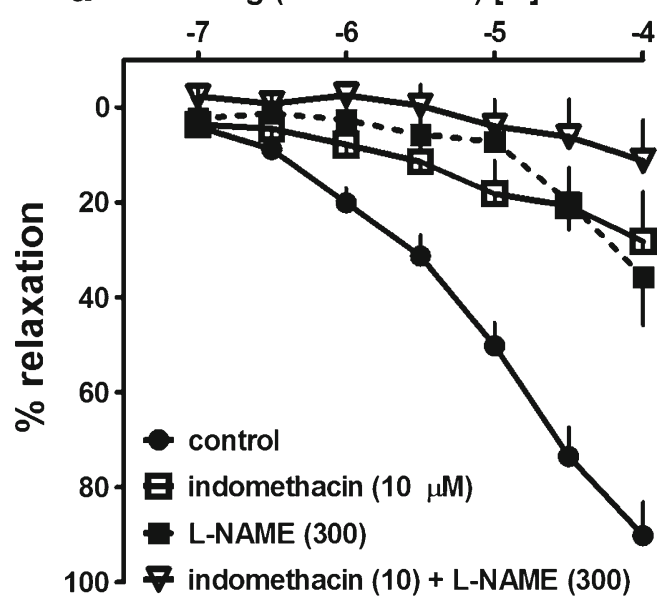

b

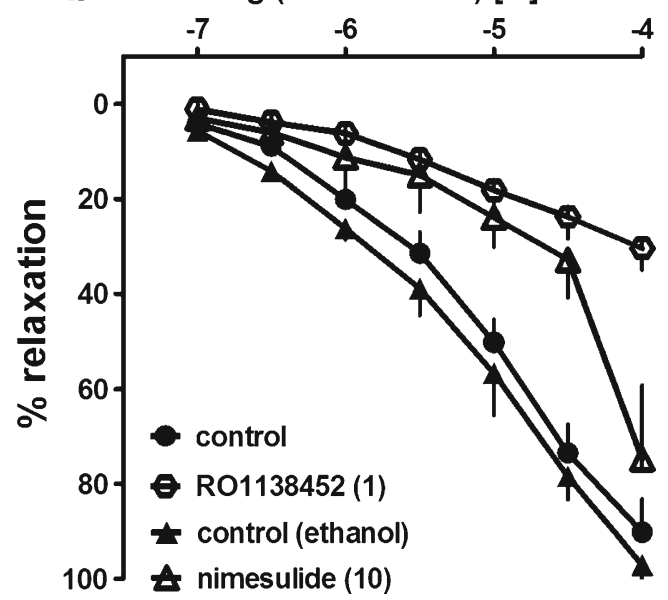

Fig. 4 Influence of a indomethacin, $N^{G}$-nitro-L-arginine methyl ester (L-NAME) given separately or in combination, and $\mathbf{b}$ nimesulide and RO1138452 on the relaxant effect of anandamide in the endothelium-intact human pulmonary artery. The results are expressed as the percentage relaxation of the isometric contraction induced by U-46619. The control concentration-response curves were obtained in the absence (related to indomethacin, L-NAME and RO1138452) or presence of ethanol (related to nimesulide). The mean \pm SEM of 3-21 tissues for each curve is presented. The SEM is smaller than or equal to the size of symbols in few cases

pre-constricted with U-46619. Therefore, the potential involvement of cannabinoid and vanilloid receptors in the vasodilatory response to anandamide was examined in endothelium-intact hPAs treated with URB597. The $\mathrm{CB}_{1}$ receptor antagonist AM251 $(1 \mu \mathrm{M})$, the $\mathrm{CB}_{2}$ receptor antagonist SR144528 $(1 \mu \mathrm{M})$ and the TRPV1 receptor antagonist capsazepine $(1 \mu \mathrm{M})$ did not affect the anandamide-induced relaxation (Fig. 6). On the other hand, O-1918 $(10 \mu \mathrm{M})$, an antagonist of the putative endothelial cannabinoid receptor, produced a fivefold rightward shift of the CRC for anandamide and reduced the relaxant effect of the highest concentration of



Fig. 5 Influence of $\mathrm{KCl}$ and iberiotoxin on the anandamide-induced relaxation in the endothelium-intact human pulmonary artery. The results are expressed as the percentage relaxation of the isometric contraction induced by $\mathrm{KCl}$ (diamonds) and U-46619 (circles and inverted triangles). The mean \pm SEM of 5-21 tissues for each curve is presented. The SEM is smaller than or equal to the size of symbols in few cases

anandamide $(100 \mu \mathrm{M})$ by about $25 \%$ (Fig. 6; for $\mathrm{pEC}_{25}$ and $R_{\max }$ values, see Table 1).

Expression of FAAH in the human pulmonary artery and lung

The expression of FAAH protein in the endothelium-intact pulmonary artery (Fig. 7, lanes 1-3) and in the lung of humans (Fig. 7, lanes 4-6) was analyzed by Western blotting with polyclonal antibodies against FAAH. Western blot analysis showed a single immunoreactive band of the molecular size expected for FAAH (63 kDa) (Fig. 7).

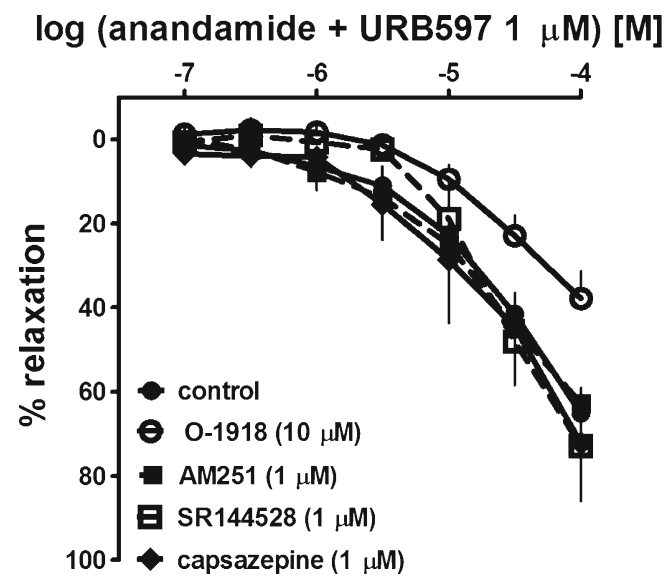

Fig. 6 Influence of AM251, SR144528, capsazepine and O-1918 on the relaxant effect of anandamide in the presence of URB597 $(1 \mu \mathrm{M})$ in the endothelium-intact human pulmonary artery. The results are expressed as the percentage relaxation of the isometric contraction induced by U-46619. The mean \pm SEM of 6-12 tissues for each curve is presented. The SEM is smaller than or equal to the size of symbols in few cases 


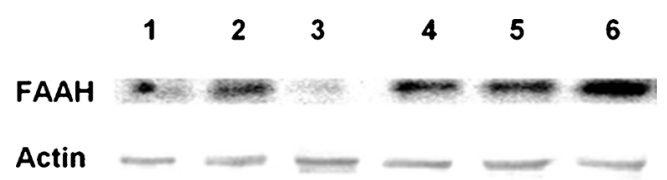

Fig. 7 Western blots for fatty acid amide hydrolase (FAAH) protein in endothelium-intact human pulmonary arteries (lanes 1-3) and lungs (lanes 4-6). Samples used for electrophoresis consisted of $100 \mu \mathrm{g}$ of protein of pooled tissue extracts $(n=6)$ obtained from three different experiments. The selectivity of the FAAH antibody was proved previously by Fowler et al. (2001). $\beta$-actin (43 kDa) was used as a loading control

\section{Discussion}

The aim of the present study was to examine the receptor(s) and mechanism(s) involved in the vasodilatory effect of AEA in hPAs. The thromboxane analogue U-46619 was used as a vasoconstrictor agent to facilitate comparisons with our work on rat pulmonary arteries (Baranowska-Kuczko et al. 2012). Moreover, thromboxane is important for the maintenance of the pulmonary tone and implicated in the development of PAH (Anderson and Nawarskas 2010).

In the present study, anandamide caused a slowly developing relaxation of the endothelium-intact hPAs yielding a $R_{\max }$ of $\sim 90 \%$ and a pEC ${ }_{50}$ of $\sim 5.0$. The possibility that the relaxant effect of anandamide is related to a direct antagonistic effect of anandamide at prostanoid TP receptors in hPAs could be excluded since anandamide at a concentration that evoked $\sim 50 \%$ relaxation $(10 \mu \mathrm{M})$ did not influence the CRC of $\mathrm{U}-46619$. The fact that anandamide showed similar potencies in preparations pre-contracted with U-46619 and serotonin $\left(\mathrm{pEC}_{50}\right.$ values of 5.0 and 4.8 , respectively) also argues against this possibility. A similar potency of anandamide was also obtained in pulmonary arteries of the rat $\left(\mathrm{pEC}_{50} 5.0\right.$; Baranowska-Kuczko et al. 2012). Moreover, the potency of anandamide in the hPAs resembled that of virodhamine $\left(\mathrm{pEC}_{50}\right.$ 5.1; Kozłowska et al. 2008). As in our previous studies, the concentrations of anandamide were in the micromolar range and similar to those occurring under pathophysiological conditions (Malinowska et al. 2012) when endocannabinoid levels are enhanced and may be relevant for vascular performance in pulmonary disorders.

The majority ( $\sim 90 \%)$ of hPAs used in our study was obtained from smokers. This might mean that the effect of anandamide represents an abnormal rather than the real physiological response. This possibility, however, is very unlikely since there was no difference in the response to this agonist in tissue taken from smoking and non-smoking patients. Moreover, the age and the sex of the patients do not influence the anandamide-induced vasorelaxation.

Endothelium plays an important physiological role in the regulation of smooth muscle tone in the pulmonary circulation. We found that the relaxant effect of anandamide on the
hPAs is to a large extent endothelium-dependent. Thus, all further experiments were carried out in rings with intact endothelium. The NO synthase inhibitor L-NAME $(300 \mu \mathrm{M}$; Kozłowska et al. 2008) strongly inhibited the anandamideinduced relaxation.

Anandamide is metabolized into arachidonic acid and ethanolamine by FAAH. Indeed, FAAH metabolism products are involved in the anandamide-induced relaxation in hPAs. First, we showed the FAAH expression in human lungs and pulmonary arteries (and could confirm the results obtained by Meng et al. (2008) and Wenzel et al. (2013) on hPA smooth muscle cells). Second, the FAAH inhibitor URB597 $(1 \mu \mathrm{M}$; Baranowska-Kuczko et al. 2012) reduced the anandamideevoked relaxation in the hPAs. The anandamide-derived arachidonic acid may be converted via COX-1 and/or COX-2 to vasoactive eicosanoids, yielding prostaglandins and prostacyclin. Both the non-selective COX inhibitor indomethacin (10 $\mu \mathrm{M}$; Baranowska-Kuczko et al. 2012) and the selective COX-2 antagonist nimesulide $(10 \mu \mathrm{M}$; Wahn et al. 2005) diminished the anandamide-induced relaxation. The reason why the attenuation of the vasorelaxation by selective COX2 inhibition was less marked when compared with combined COX-1 plus COX-2 inhibition may be that an exposure to anandamide lasting for $>1 \mathrm{~h}$ is required to fully induce COX-2 expression (Chen et al. 2005).

In the pulmonary circulation, the IP receptor is detected ( $\mathrm{Li}$ et al. 2012) and prostacyclin is a particularly important product of COX (Kuwano et al. 2008; Waxman and Zamanian 2013; Benyahia et al. 2013). We found that the IP receptor antagonist RO1138452 (1 $\mu \mathrm{M}$; Kozłowska et al. 2012; Baranowska-Kuczko et al. 2012) reduced the anandamidemediated relaxation of the hPAs. Moreover, the extent of attenuation of the anandamide-evoked relaxation is similar to that obtained with indomethacin. Our data suggest that the IP receptor is involved in the anandamide-mediated response in the hPAs and are comparable to the results obtained in the rat pulmonary arteries $\left(\mathrm{pA}_{2}=6.2\right.$; Baranowska-Kuczko et al. 2012). Since the effect of L-NAME and indomethacin almost equalled that of endothelial removal and the dual inhibition of NO and COX-1/2 and almost completely abolish the effect of anandamide, one can conclude that the endotheliumdependent relaxation of the hPAs induced by anandamide is mainly due to NO and COX-dependent pathways.

Two sets of experiments suggest the involvement of potassium channels in the effect of anandamide. First, the relaxation to anandamide was almost completely abolished in the hPAs pre-constricted with a high concentration of $\mathrm{KCl}(60 \mathrm{mM}$; Kozłowska et al. 2008). Such experimental conditions depolarize the hPAs by inhibiting the potassium ion efflux. Second, iberiotoxin $(0.1 \mu \mathrm{M}$; Galvez et al. 1990), a selective inhibitor of the large-conductance calcium-dependent potassium channels, strongly reduced the relaxant effect of anandamide. The $\mathrm{BK}_{\mathrm{Ca}}$ channels may be activated by vasoactive anandamide 
degradation products (arachidonic acid and derivatives; Gauthier et al. 2005) or by NO in the hPAs (Guerard et al. 2004). In addition, increased intracellular $\mathrm{Ca}^{2+}$ could release endothelial vasorelaxants, including $\mathrm{NO}$ and $\mathrm{PGI}_{2}$ (Félétou 2009). It is therefore possible that COX-dependent products of AEA-derived arachidonic acid induce the release of NO which in turn acts in the hPA via $\mathrm{K}_{\mathrm{Ca}}$ channel opening.

Anandamide mediates its cardiovascular effects through cannabinoid $\mathrm{CB}_{1}$ and $\mathrm{CB}_{2}$ receptors, the O-1918-sensitive endothelial cannabinoid receptor and the vanilloid TRPV1 receptor (Montecucco and Di Marzo 2012; Malinowska et al. 2012). To eliminate the influence of anandamide metabolites, all experiments aimed at the determination of cannabinoid-sensitive receptors were performed in the presence of URB $597(1 \mu \mathrm{M}) . \mathrm{CB}_{1}$ receptors are not involved in the AEA-mediated vasorelaxation since the respective receptor antagonist AM251 (1 $\mu \mathrm{M}$; Wheal et al. 2010) did not influence the $\mathrm{CRC}$ of anandamide. The involvement of $\mathrm{CB}_{2}$ and vanilloid TRPV1 receptors could also be excluded since the respective antagonists at these receptors, SR144528 $(1 \mu \mathrm{M}$; Kozłowska et al. 2008) and capsazepine $(1 \mu \mathrm{M}$; Tamaki et al. 2012), failed to modify the vasorelaxant effect of anandamide. By contrast, O-1918 $\left(10 \mu \mathrm{M} ; \mathrm{pA}_{2}=6.3\right.$ and 6.0; Kozłowska et al. 2008; Baranowska-Kuczko et al. 2012, respectively) shifted to the right of the CRC for anandamide, suggesting that this receptor plays a role in the anandamideinduced vasorelaxation.

The quantitative role of unmetabolized anandamide appears to be lower than that played by the COX product. The mechanism behind the vasodilator effect of unmetabolized anandamide has not been studied in the present work; however, in our previous paper on the same preparation, abnormal cannabidiol (which like anandamide activates the endothelial cannabinoid receptor but is not metabolized) was shown to act via the endothelium and the activation of $\mathrm{Ca}^{2+}$-activated potassium channels (Kozłowska et al. 2007).

The present work (in combination with our previous studies: Kozłowska et al. 2007; 2008) on hPA is qualitatively similar to our study on the rat pulmonary artery (Baranowska-Kuczko et al. 2012); the extent of vasodilatation was even more marked in the human than in the rat pulmonary artery. In those experiments, pre-constricted pulmonary arteries were used; in non-pre-constricted vessels, anandamide had no effect at all in pulmonary arteries of rats (BaranowskaKuczko et al. 2012), humans (present study) and mice (Wenzel et al. 2013). In the isolated perfused lung of the mouse (Wenzel et al. 2013) and the rabbit (Wahn et al. 2005), anandamide caused an increase in the perfusion pressure (reflecting a vasopressor response). The isolated lung model mainly reflects vessels of the pulmonary circulation with a small calibre. Although the data obtained from the isolated perfused lung are of particular interest with respect to in vivo conditions, one has to consider that, in the pulmonary unlike the systemic circulation, there are no typical resistance vessels (Saouti et al. 2010). In order to have a comprehensive view, it therefore appears necessary to consider the contradictory results obtained on the pulmonary arteries and in the isolated perfused lung preparation in combination. The reason why anandamide acts so differently in the two experimental models is unclear but it is of interest that this endocannabinoid behaved as a vasodilator, vasoconstrictor or was without vascular activity also in vessels of the systemic circulation, depending on the calibre and/or the vascular tone (White and Hiley 1998; Vanheel and Van de Voorde 2001). With respect to the results in the pulmonary circulation, it is intriguing that the pathways for vasodilatation and vasoconstriction resemble each other. So, FAAH plays a role both for endothelium-dependent vasodilatation (Baranowska-Kuczko et al. 2012; present study) and endothelium-independent vasoconstriction (Wahn et al. 2005; Wenzel et al. 2013). With respect to the subsequent step, $\mathrm{COX}$ is implicated both in the vasodilatation (Baranowska-Kuczko et al. 2012; present study) and vasoconstriction (Wahn et al. 2005; Wenzel et al. 2013). Thus, one should be somewhat more cautious when suggesting the potential use of FAAH inhibitors for the treatment of PAH (Wenzel et al. 2013) or other diseases (e.g. Bisogno and Maccarrone 2013).

\section{Conclusions}

In conclusion, our findings show that anandamide relaxes hPAs. The vascular response to anandamide is almost totally endothelium-dependent and involves the opening of potassium channels and stimulation of NO release that, in turn, may be the result of activation of the putative O-1918-sensitive cannabinoid receptor or production of COX-sensitive prostacyclin-like vasoactive products.

Acknowledgments This study was supported by grants from the Medical University of Białystok (124-13505F, 123-13884F).

Conflict of interest The authors declare that they have no conflict of interest.

Open Access This article is distributed under the terms of the Creative Commons Attribution License which permits any use, distribution, and reproduction in any medium, provided the original author(s) and the source are credited.

\section{References}

Anderson JR, Nawarskas JJ (2010) Pharmacotherapeutic management of pulmonary arterial hypertension. Cardiol Rev 18:148-162

Baranowska-Kuczko M, MacLean MR, Kozłowska H, Malinowska B (2012) Endothelium-dependent mechanisms of the vasodilatory 
effect of the endocannabinoid, anandamide, in the rat pulmonary artery. Pharmacol Res 66:251-259

Benyahia C, Boukais K, Gomez I, Silverstein A, Clapp L, Fabre A, Danel C, Leséche G, Longrois D, Norel X (2013) A comparative study of $\mathrm{PGI}_{2}$ mimetics used clinically on the vasorelaxation of human pulmonary arteries and veins, role of the DP-receptor. Prostaglandins Other Lipid Mediat 107:48-55. doi:10.1016/j. prostaglandins.2013.07.001

Bisogno T, Maccarrone M (2013) Latest advances in the discovery of fatty acid amide hydrolase inhibitors. Expert Opin Drug Discov 8: 509-522

Calignano A, Kátona I, Désarnaud F, Giuffrida A, La Rana G, Mackie K, Freund TF, Piomelli D (2000) Bidirectional control of airway responsiveness by endogenous cannabinoids. Nature 408:96-101

Chen P, Hu S, Yao J, Moore SA, Spector AA, Fang X (2005) Induction of cyclooxygenase-2 by anandamide in cerebral microvascular endothelium. Microvasc Res 69:28-35

Félétou M (2009) Calcium-activated potassium channels and endothelial dysfunction: therapeutic options? Br J Pharmacol 156:545-562

Fowler CJ, Jonsson K, Tiger G (2001) Fatty acid amide hydrolase: biochemistry, pharmacology, and therapeutic possibilities for an enzyme hydrolyzing anandamide, 2-arachidonoylglycerol, palmitoylethanolamide, and oleamide. Biochem Pharmacol 62: $517-526$

Frumkin LR (2012) The pharmacological treatment of pulmonary arterial hypertension. Pharmacol Rev 64:583-620

Galvez A, Gimenez-Gallego G, Reuben JP, Roy-Contancin L, Feigenbaum P, Kaczorowski GJ, Garcia ML (1990) Purification and characterization of a unique, potent, peptidyl probe for the high conductance calcium-activated potassium channel from venom of the scorpion Buthus tamulus. J Biol Chem 265:11083-11090

Gauthier KM, Baewer DV, Hittner S, Hillard CJ, Nithipatikom K, Reddy DS, Falck JR, Campbell WB (2005) Endothelium-derived 2arachidonylglycerol: an intermediate in vasodilatory eicosanoid release in bovine coronary arteries. Am J Physiol Heart Circ Physiol 288:H1344-H1351

Guerard P, Goirand F, Fichet N, Bernard A, Rochette L, Morcillo EJ, Dumas M, Bardou M (2004) Arachidonic acid relaxes human pulmonary arteries through $\mathrm{K}^{+}$channels and nitric oxide pathways. Eur J Pharmacol 501:127-135

Hornig B (2007) Endothelial vasodilatory cannabinoid receptor in the human pulmonary artery: a future option in the therapy of pulmonary hypertension? J Hypertens 25:2202-2203

Kozłowska H, Baranowska M, Schlicker E, Kozłowski M, Laudański J, Malinowska B (2007) Identification of the vasodilatory endothelial cannabinoid receptor in the human pulmonary artery. J Hypertens 25:2240-2248

Kozłowska H, Baranowska M, Schlicker E, Kozłowski M, Laudański J, Malinowska B (2008) Virodhamine relaxes the human pulmonary artery through the endothelial cannabinoid receptor and indirectly through a COX product. Br J Pharmacol 155:1034-1042

Kozłowska H, Baranowska-Kuczko M, Schlicker E, Kozłowski M, Zakrzeska A, Grzęda E, Malinowska B (2012) $\mathrm{EP}_{3}$ receptormediated contraction of human pulmonary arteries and inhibition of neurogenic tachycardia in pithed rats. Pharmacol Rep 64:1526 1536

Kuwano K, Hashino A, Noda K, Kosugi K, Kuwabara K (2008) A longacting and highly selective prostacyclin receptor agonist prodrug, 2$\{4$-[(5,6-diphenylpyrazin-2-yl)(isopropyl)amino]butoxy $\}-N$ - (methylsulfonyl)acetamide (NS-304), ameliorates rat pulmonary hypertension with unique relaxant responses of its active form, \{4[(5,6-diphenylpyrazin-2-yl)(isopropyl)amino]butoxy $\}$ acetic acid (MRE-269), on rat pulmonary artery. J Pharmacol Exp Ther 326: 691-699

Laemmli UK (1970) Cleavage of structural proteins during the assembly of the head of bacteriophage T4. Nature 227:680-685

Li Y, Connolly M, Nagaraj C, Tang B, Bálint Z, Popper H, SmolleJuettner FM, Lindenmann J, Kwapiszewska G, Aaronson PI, Wohlkoenig C, Leithner K, Olschewski H, Olschewski A (2012) Peroxisome proliferator-activated receptor- $\beta / \delta$, the acute signaling factor in prostacyclin-induced pulmonary vasodilation. Am J Respir Cell Mol Biol 46:372-379

Malinowska B, Baranowska-Kuczko M, Schlicker E (2012) Triphasic blood pressure responses to cannabinoids: do we understand the mechanism? Br J Pharmacol 165:2073-2088

Meng F, To WK, Gu Y (2008) Inhibition effect of arachidonic acid on hypoxia-induced $\left[\mathrm{Ca}^{2+}\right]_{\mathrm{i}}$ elevation in $\mathrm{PC} 12$ cells and human pulmonary artery smooth muscle cells. Respir Physiol Neurobiol 162:18-23

Montecucco F, Di Marzo V (2012) At the heart of the matter: the endocannabinoid system in cardiovascular function and dysfunction. Trends Pharmacol Sci 33:331-340

Pertwee RG, Howlett AC, Abood ME, Alexander SP, Di Marzo V, Elphick MR, Greasley PJ, Hansen HS, Kunos G, Mackie K, Mechoulam R, Ross RA (2010) International Union of Basic and Clinical Pharmacology. LXXIX. Cannabinoid receptors and their ligands: beyond $\mathrm{CB}_{1}$ and $\mathrm{CB}_{2}$. Pharmacol Rev 62:588-631

Saouti N, Westerhof N, Postmus PE, Vonk-Noordegraaf A (2010) The arterial load in pulmonary hypertension. Eur Respir Rev 19:197203

$\mathrm{Su}$ JY, Vo AC (2007) 2-Arachidonylglyceryl ether and abnormal cannabidiol-induced vascular smooth muscle relaxation in rabbit pulmonary arteries via receptor-pertussis toxin sensitive $G$ proteins-ERK1/2 signaling. Eur J Pharmacol 59:189-195

Tamaki C, Nawa H, Takatori S, Oda S, Sendo T, Zamami Y, Kawasaki H (2012) Anandamide induces endothelium-dependent vasoconstriction and CGRPergic nerve-mediated vasodilatation in the rat mesenteric vascular bed. J Pharmacol Sci 118:496-505

Vanheel B, Van de Voorde J (2001) Regional differences in anandamideand methanandamide-induced membrane potential changes in rat mesenteric arteries. J Pharmacol Exp Ther 296:322-328

Wahn H, Wolf J, Kram F, Frantz S, Wagner JA (2005) The endocannabinoid arachidonyl ethanolamide (anandamide) increases pulmonary arterial pressure via cyclooxygenase- 2 products in isolated rabbit lungs. Am J Physiol Heart Circ Physiol 289:H2491$\mathrm{H} 2496$

Waxman AB, Zamanian RT (2013) Pulmonary arterial hypertension: new insights into the optimal role of current and emerging prostacyclin therapies. Am J Cardiol 111:1A-19A

Wenzel D, Matthey M, Bindila L, Lerner R, Lutz B, Zimmer A, Fleischmann BK (2013) Endocannabinoid anandamide mediates hypoxic pulmonary vasoconstriction. Proc Natl Acad Sci U S A 110:18710-18715. doi:10.1073/pnas.1308130110

Wheal AJ, Alexander SP, Randall MD (2010) Vasorelaxation to $N$ oleoylethanolamine in rat isolated arteries: mechanisms of action and modulation via cyclooxygenase activity. Br J Pharmacol 160: $701-711$

White R, Hiley CR (1998) The actions of some cannabinoid receptor ligands in the rat isolated mesenteric artery. Br J Pharmacol 125: $533-541$ 